\title{
Üst Ekstremite Tuzak Nöropatileri
}

Peripheral nerve entrapment in the upper extremity Ahmet Karakoyun ${ }^{1}$ (D), Yalkın Çalık ${ }^{2}$ (i)

1 Fiziksel Tıp ve Rehabilitasyon ABD, Aksaray Üniversitesi Tıp Fakültesi, Aksaray/Türkiye

\section{özeT}

Tuzak nöropatiler periferik sinirlerin üzerindeki akut, intermittant, tekrarlayıcı veya devamlı baskı altında kalması sonucunda belli noktalarda ortaya çıkan, motor, duyu ve otonom bozuklukların eşlik ettiği tablodur. Tuzak nöropatiler, daha çok üst ekstremitede görülür; bunlar arasında da en sık görülenleri, median sinirin bilek seviyesinde sıkışması olan karpal tünel sendromudur. Tanıda doğru bir öykü, fizik muayene, özel testler(Tinel testi, Phalen testi), radyolojik incelemeler ve elektrofizyolojik incelemeler destekleyici yöntemler olarak kullanılmaktadır. Tuzak nöropati oluşumunda travma, vasküler patolojiler, inflamatuar ve otoimmün hastalıklar, endokrin ve metabolik bozukluklar, hormonal ve tümöral nedenler etkilidir. Tuzak nöropatilerde sinirin duysal alanına lokalize parestezi olması, yanma, karıncalanma, batma, kaşıntı, kas ağrısı bulunması, özellikle gece ağrısının fazla olması, kronik basıda kas güçsüzlüğü ve atrofisinin olması gibi klinik özellikleri bulunabilir. Tedavide splintleme, enjeksiyonlar, fizik tedavi modaliteleri ve cerrahi uygulamalar yer almaktadır.

Anahtar Kelimeler: karpal tünel sendromu, üst ekstremite, median sinir, ulnar sinir

\section{ABSTRACT}

Trap neuropathies are accompanied by motor, sensory and autonomic disorders that occur at certain points as a result of acute, intermittent, repetitive or sustained pressure on the peripheral nerve. Trap neuropathies are more common in the upper extremity; the most common of these is carpal tunnel syndrome which is the compression of the median nerve at the wrist. $A$ correct history, physical examination, special tests(Tinel test, Phalen test), radiological examinations and electrophysiological investigations supporting the findings are used as supportive methods. Trauma, vascular pathologies, inflammatory and autoimmune diseases, endocrine and metabolic disorders, hormonal and tumoral factors are effective in the formation of trap neuropathy. In trap neuropathies, there may be localized paresthesias to the sensory area of the nerve, burning, tingling, stinging, itching, muscle pain, especially night pain, the presence of muscle weakness and atrophy in chronic press. Treatment includes splinting, injections, physical therapy modalities and surgical applications.

Key Words: carpal tunnel syndrome, upper extremity, median nerve, ulnar nerve

\section{Tanım ve Genel Bilgiler}

Tuzak nöropatiler, periferik sinirin anatomik seyri boyunca belli noktalarda farklı nedenlerden dolayı sıkışması sonucu ortaya çıkan, motor, duyu ve otonom defisitlerle karakterize tablodur. Tuzak nöropatiler, üst ekstremitede en sık karşılaşılan problemlerdendir. Genel anlamda, 25-40 yaş arasındaki aktif çalışan genç/orta yaşı bireylerde, özellikle mesleki faktörlere bağlı olarak; 40-60 yaş arasındaki bireylerde ise metabolik/hormonal faktörler nedeniyle ortaya çıktığı düşünülmektedir. "Tuzak”, "kompresyon” veya benzeri terimler, sorunun başlangıcının sinir kaynaklı olmadığını, dış mekanik etkilere ikincil olarak geliştiğini belirtmek amacı ile kullanılır $(1,2)$. Özellikle genç bireylerde daha sık görülmesi nedeniyle, iş gücü kaybına da neden olmaktadır $(3,4)$. Tuzak nöropatilerinde tanı klinik olarak konur ve genellikle sinir iletim çalışmalarından (Elektronöromyografi-ENMG) da yararlanılır $(5,6)$. Sıkışma sonrasında ilgili periferik sinirin innerve ettiği alanda, motor, duyu ve otonom problemler ortaya çıkar. Akut tuzaklanmalarda geçici iskemik blok nedeniyle, epinöral kan akımı ve aksonal transport azalır, geçici iletim problemleri ile karşılaşııı ve konservatif tedaviden yarar görür. Bası zamanı arttıkça, sinirde meydana gelen hasarın miktarı da artar ve morfolojik değişiklikler oluşmaya başlar. Orta dereceli bası sonucunda, intranöronal mikrosirkülasyon bozulur, epinöral ve intrafasiküler ödem oluşur; intranöronal fibrozis meydana gelebilir. Bu dönemde, provokatif testler pozitiftir. Vibrasyon duyusunda azalma ve tenar kaslarda zayıflık söz konusudur. Hasta, genellikle anormal olan bir duyudan bahseder. Ciddi dereceli bası

Yazışma Adresi/Address for Correspondence: Ahmet Karakoyun, MD, Fiziksel Tıp ve Rehabilitasyon Anabilim Dalı, Aksaray Üniversitesi Tıp Fakültesi, Aksaray/Türkiye

E-Posta/E-Mail: furkankk42@hotmail.com || Tel: +90 $3822882900(3216)$

Received/Geliş Tarihi: 10.11.2018 || Accepted/Kabul Tarihi: 04.12.2018

Bu Eser Creative Commons Atıf-Gayriticari 4.0 Uluslararası Lisansı İle Lisanslanmıştır. This work is licensed under a Creative Commons

Attribution-NonCommercial 4.0 International License (CC BY-NC 4.0). 
sonrasında ise, uzun süre devam eden epinöral ödemi endonöral ödem ve fibrozis takip eder ve segmental demiyelinizasyon daha da kronikleşirse Wallerian dejenerasyon başlar. ENMG bu dönemde sinir tarafından innerve edilen kaslarda denervasyonu gösterir. Duyu problemleri (iki nokta ayrımı >2 $\mathrm{mm}$ ) ve kaslarda atrofi söz konusudur (2,7). Tuzak nöropatilerdeki ilk semptom, genellikle periferik sinirin otonom ve duyu liflerinin etkilenmesine bağlı, ilgili sinirin dermatom alanında ortaya çıkan, yanma, uyuşma ve karıncalanma hissidir. Bu his, özellikle geceleri ve istirahat halindeyken daha da artar. Eğer periferik sinirin motor liflerinde de etkilenme söz konusu ise, kaslarda güçsüzlük, ileri dönemde atrofi ve beraberinde gelen fonksiyonel yetersizlikler (beceri kaybı, günlük yaşam aktivitelerini yerine getirmede problemler) tabloya eşlik eder $(8,9)$. Tuzak nöropatiler Seddon ve Sunderland tarafından sınıflandırılmıştır (Tablo-1).

\begin{tabular}{|c|c|c|}
\hline Seddon & Sunderland & \\
\hline Nöropraksi & Evre I & İletim bloğu \\
\hline Aksonotmezis & Evre II & Akson etkilenmiş, epinörium sağlam \\
\hline & Evre III & $\begin{array}{c}\text { Akson ve endonöral tüp devamlılı̆̆ı } \\
\text { bozulmuş, perinörium ve funikuluslar } \\
\text { sağlam }\end{array}$ \\
\hline & Evre IV & $\begin{array}{c}\text { Aksonlar, endonöral tüpler, perinörium ve } \\
\text { funikulusların devamlılı̆ı bozulmuş, } \\
\text { epinörium sağlam }\end{array}$ \\
\hline Nörotmezis & Evre V & $\begin{array}{l}\text { Tüm sinir trunkusların devamlılı̆ı } \\
\text { bozulmuş }\end{array}$ \\
\hline
\end{tabular}

\section{Üst Ekstremite Tuzak Nöropatileri}

\section{Boyun Seviyesindeki Kompresyon Nöropatileri}

\section{Servikal Kosta Sendromu}

Servikal kostanın veya C7 transvers uzantısının, brakial pleksusun C8 ve T1 köklerine baskı yapıp, elde duyusal ve motor kayıplara neden olmasıdır. Genelde önkol iç yüzünde ve son iki parmakta (yüzük ve küçük parmaklar) duyu kusuru olur. Üst ekstremitede ağrı, elde intrinsik kaslarda atrofi, vazomotor değişiklikler olabilir. Konservatif tedavi başarısız olursa cerrahi tedavi yapılır (3).

Scalenius Anterior Sendromu

Brakial pleksusun, m.scalenius arasından geçerken sıkışmasıyla gelişir. O taraf ekstremitede vasküler yetersizlik ve kladikasyo oluşur (3).

\section{Torasik Outlet Sendromu}

Üst ekstremitenin nörovasküler yapısının sıkışmasına bağlı gelişen kompleks durumdur. Brakial pleksus, özellikle alt trunkus, subklavian arter ve ven, klavikula ve 1 . kosta arasında sıkışmaktadırlar (Şekil-1). \%25 oranında kadınlarda daha sık görülür. İlk şikâyet ağrı olabilir ve boyun ve omuzdan ele kadar yayılabilir. Önkolun ve elin iç yüzünde parestezi eşlik eder. Şikayetler, el omuzun üstünde iken çalışmayı gerektiren durumlarda artar. Ağrı sıklıkla gece uykudan uyandırır. Soğuk entolerans, renk değişliklikleri veya Raynaud fenomeni olabilir. Konservatif tedavi başarısız olduğunda cerrahi tedaviye gidilmelidir $(4,5)$.

Şekil 1.

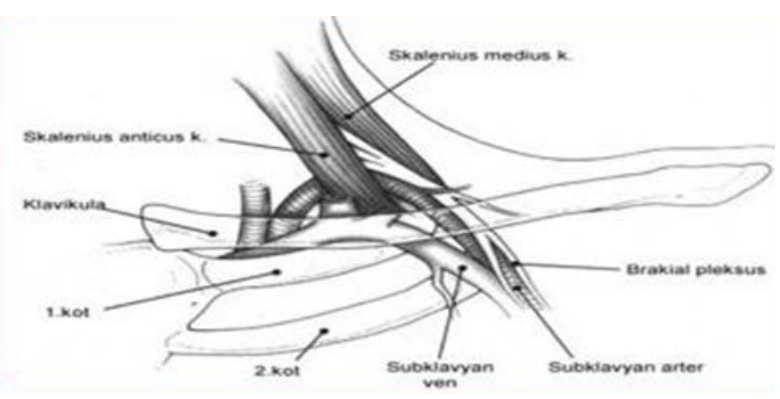

Median Sinir Tuzak Nöropatileri

C6-T1 spinal sinir köklerinden innerve olan median sinir brakiyal pleksusun üst-orta-alt trunkusundan oluşur.

\section{Karpal Tünel Sendromu (KTS)}

Median sinirin el bileği seviyesinde karpal transvers bağ altında sıkışmasıdır (Şekil-2). KTS en sık görülen tuzak nöropatidir. Popülasyonun genelinde $\% 3$, endüstrileşmiş toplumlarda \%5-15, 40-60 yaş arası kadınlarda, erkeklere oranla daha sık rastlanan bir sendromdur. Başlıca şikayetler elin ilk üç parmağında ağrı, karıncalanma ve uyuşukluktur. Daha çok bilateral olarak ortaya çıkar. Hastalar daha çok geceleri yada sabah ellerinde uyuşma şikayeti ile uyandıklarını söylerler. Eli sallama ile şikayetlerin azaldığı rapor edilmiştir. Bu hastalarda tablo genellikle idiyopatik olarak oluşsa da, diyabet, tiroid gibi bazı sistemik hastalıklar, hamilelik ve mesleki koşullar da KTS nedenleri arasında sayılabilir. Karpal tünel sendromu tanısı klinik olarak konur ve genellikle ENMG de yararlı olur $(3,5,6)$. Semptomları şiddetli olmayan erken evredeki hastalarda elektofizyolojik testler normal olabilir. Tanı koymaya yardımcı Phalen ve Tinel testleri gibi bazı provakatif testler bulunmaktadır (Şekil-3). Phalen testi, 1dk süresince el bileğinin fleksiyonda tutulmasılyla parestezi gelişmesidir. Tinel testi ise, el bileği ekstansiyonda iken karpal tünel üzerine yapılan baskı ile parestezi oluşmasıdır. KTS'de zamanla motor liflerin de etkilenmeye başlamasıyla, 2. ve 3. parmağın lumbrikal kaslarında atrofi oluşmaya başlar ve 
hastada, elde güçsüzlük, beceriksizlik (elden bir şeyler düşürme, ince el becerilerini yapamama) şikayetleri de gelişmeye başlar. Özellikle, el bileğinin uzun süreli fleksiyon veya ekstansiyon pozisyonunda kullanılması, semptomları daha da arttırır (3). KTS'de, konservatif yaklaşımlar veya cerrahi tedavi uygulanabilir. Tedavide amaç, median sinir üzerindeki kompresyon kuvvetini azaltmaktır. Konservatif yaklaşımlar, fleksör tendon sinoviyumundaki inflamasyonu azaltmayı hedefler. Konservatif tedavinin ilk basamağı, irrite olmuş dokuları dinlendirmek için uygulanacak splint tedavisidir. Hastalardan, 3-4 hafta süreyle ve özellikle geceleri, el bileğini ve metakarpofalangeal (MCP) eklemi nötral pozisyonda tutan bu splintleri hiç çıkarmadan kullanması istenir $(3,9)$. Diğer konservatif tedavi yöntemleri olarak splintleme dışında, non steroid antiinflamatuvar ilaçlar, steroid enjeksiyonu, fizik tedavi modaliteleri (en sık ultrason, parafin, iyontoforez, TENS, lazer, masaj, tendon ve sinir kaydırma egzersizleri), el terapisi uygulamaları ve iş yeri modifikasyonları, en yaygın kullanılan yöntemlerdir $(3,4,10,11)$. Semptomlar azalmaya başladığı an, splint çıkarılabilir ve programa, el bileği ve parmakları içine alan germe egzersizleri eklenir. Yine, zayıflık olan kaslara kuvvetlendirme egzersizleri verilmelidir. Konservatif tedavilere rağmen 8-12 hafta sonra belirgin bir iyileşme görülmüyorsa, cerrahi tedavi endikedir $(3,9)$.

\section{Şekil 2.}
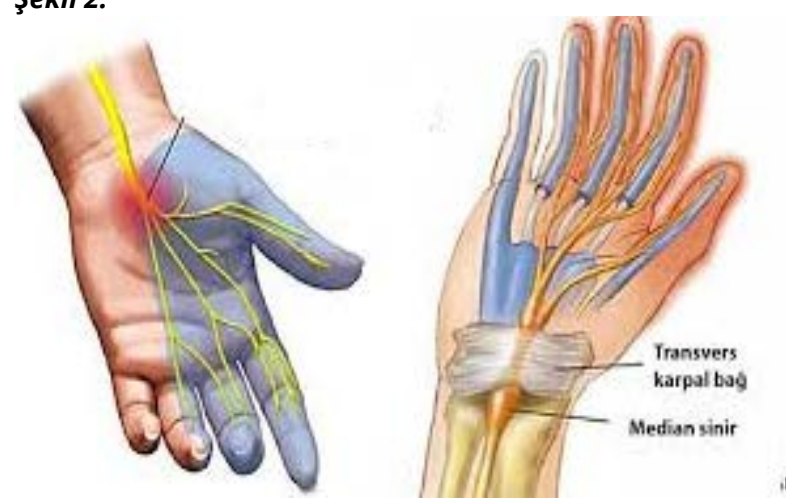

Şekil 3.

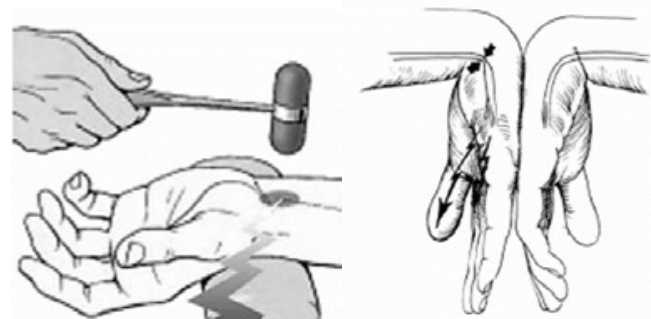

Konservatif tedavi ile düzelmeyen durumlarda cerrahi tedavi düşünülmelidir. Cerrahi tedavide karpal tünel gevşetme ameliyatları yapılmaktadır. Karpal tünel gevşetme ameliyatı, transvers karpal bağın gevşetilerek, median sinir için karpal tünelde daha fazla yer açmak ve basıncı azaltmak amacıyla, açık ve endoskopik olmak üzere iki farklı şekilde uygulanır. Her iki ameliyatın da, birbirine göre avantaj ve dezavantajları vardır. El rehabilitasyonu yönünden baktığımızda, endoskopik cerrahilerin, daha az skar oluşumu ve karpal tünel üzerinde insizyon oluşturmaması nedeniyle, daha avantajlı olduğu söylenebilir. Aynı zamanda, yapılan çalışmalar, endoskopik cerrahi sonrası işe geri dönüş süresinin çok daha kısa olduğunu göstermektedir $(11,12,13)$. Cerrahi sonrası el terapisi uygulamaları, mümkün olan en erken dönemde başlamalıdır. Gerek açık gerekse endoskopik olarak yapılan karpal tünel gevşetme ameliyatları sonrasında, parmak hareketlerine ilk gün içerisinde başlanırken, el bileği hareketlerine genellikle 5-7 gün içerisinde başlanır. İşe geri dönüş, açık cerrahi sonrası 4.-6. haftalar arasında gerçekleşirken, endoskopik cerrahiyi takiben üç hafta sonrasında gerçekleştiği belirtilmektedir (14).

\section{Anterior interosseöz Sendrom:}

Median sinirin motor dalı olan anterior interosseous'un başlangıç noktasında sıkışmasıdır. Önkolun proksimalinde, aktivite ile artan bir ağrı vardır. Hastalar fleksör pollisis longus ve 2. parmak fleksör dijitorum profundus kaslarının çalışmaması nedeniyle, pinch kavrama sırasında, bu iki parmak distal interfalangeal ekleminde fleksiyon hareketini gerçekleştiremez. Martin-Gruber anastomozu nedeniyle, elin intrensek kaslarında da paralizi tablosu oluşabilir $(3,8)$. Tedavisi konservatiftir, fizik tedavi uygulamaları, tekrarlayan ön kol hareketlerinden kaçınma, splintleme, enjeksiyonlar önerilir.

\section{Pronator teres Sendromu:}

Median sinirin, pronator teres kasının iki başı arasında sıkışmasıyla veya fibröz bantların baskısı sonucunda oluşur. Dirençli el bileği fleksiyon ve önkol pronasyonu ile semptomlar artar. Ağrı önkolun medialine lokalizedir. Median sinirin dermatom sahası olan elin ilk üç parmağında, parestezi ve duyu problemleri görülür (8). Tedavisinde genellikle konservatif tedavi tercih edilir (3). Konservatif tedavinin ilk basamağı, irrite olmuş dokuları dinlendirmek için uygulanacak dirseği $90^{\circ}$ fleksiyonda ve 
önkolu nötral pozisyonda tutan uzun kol splint uygulamasıdır. Hastadan, 3-4 hafta süreyle ve gün içerisinde, bu splinti hiç çıkarmadan kullanması istenir (9). Ağrı tedavisi için, farklı elektriksel modaliteler, masaj, yumuşak doku mobilizasyonu ve soğuk uygulaması kullanılabilir. Semptomlar dinlenme sırasında azalmaya başladığı an, splint çıkarılır ve programa, dirsek ve el bileğini içeren germe egzersizleri eklenir. Yine, zayıflık olan kaslara kuvvetlendirme egzersizleri verilmelidir (3). Konservatif tedaviden 8-12 hafta sonra iyileşme yoksa, cerrahi tedavi endikedir. Dekompresyon cerrahisini takiben, mümkün olan en erken dönemde aktif normal eklem hareketlerine başlanmalı ve 7.-10. günlerde kuvvetlendirme egzersizlerine geçilmelidir $(3,9)$.

\section{Suprakondiler Proses Sendromu:}

Median sinirin Struthers bağı ve distal humerusta olan kemiksi çıkıntı arasında sıkışmasıyla oluşur. Klinik olarak asimetrik ve nadir olan tuzak nöropatidir. Tanıda direk radyografilerde humerus distalde kemik çıkıntının görülmesi ve klinikte humerus distalden ele doğru yayılan ağrı olması önemlidir. Konservatif tedavi ile rahatlama olmayanlara cerrahi önerilebilir (9).

\section{Ulnar Sinir Tuzak Nöropatileri}

\section{Kubital Tünel Sendromu:}

Kübital tünel sendromu, karpal tünel sendromundan sonra ikinci en sık görülen sıkışma sendromudur. Ulnar sinirin dirsek seviyesinde tuzaklanması sonucunda gelişir (Şekil-4). Sebepleri arasında, sistemik hastalıklar, uzun süreli turnike uygulaması, mediyal epikondil kırı̆̆ı, kubitus valgus deformitesi, tekrarlı dirsek fleksiyon-ekstansiyonunu veya dirseğin uzun süre bir yere dayanmasını gerektiren aktiviteleri içeren meslekler ve dirsek fleksiyonda uyuma gibi, farklı nedenleri olabilir. Dirsek tam fleksiyonda iken, kübital tünel en dar konumdadır; bu da, sinirin kompresyona uğramasına neden olur. Şikayet genellikle önkolun mediyaline yayılan ağrı, elin dorsal ve palmar yüzünde duyu anormallikleri ve elin intrensek adalelerinde motor zayıflık şeklindedir $(15,16)$. Ilerlemiş dönemlerde, pençe el deformitesi (4. ve 5. parmakların MP eklemlerinin hiperekstansiyona, PIP ve DIP eklemlerin ekstrensik fleksörlerin etkisi ile fleksiyona gitmesi) meydana gelebilir. Hafif ve orta dereceli bası olan bütün hastalara, konservatif tedavi önerilir. Literatürde, hafif kübital tünel basısı olan hastalarda konservatif tedavinin başarı oranı \%58 olarak bildirilmiştir (17). Kübital tünel sendromunun konservatif tedavisinde, dirsek fleksiyonunu limitleyerek kübital tüneldeki ulnar sinir üzerinde daha fazla kompresyon oluşmasına engel olmak için, statik uzun kol splinti önemlidir. Splint, dirseği $45-60^{\circ}$ arasında fleksiyonda, el bileğini nötralde tutan, parmakların serbest olduğu bir splinttir. Bu splint, gece gündüz üç hafta boyunca kullanılır $(9,18)$. Üç-altı haftalık konservatif tedavi sonrası semptomlarda azalma meydana gelmemesi durumunda, cerrahi yöntemler düşünülebilir $(10,11)$. Kübital tünel dekompresyon cerrahisi sonrası rehabilitasyon programı karpal tünel sendromundaki gibi koruma yöntemleri, splintleme, fizik tedavi programları, germe ve kuvvetlendirme egzersizleri şeklinde rehabilitasyon programına başlanmalıdır.

Şekil 4.

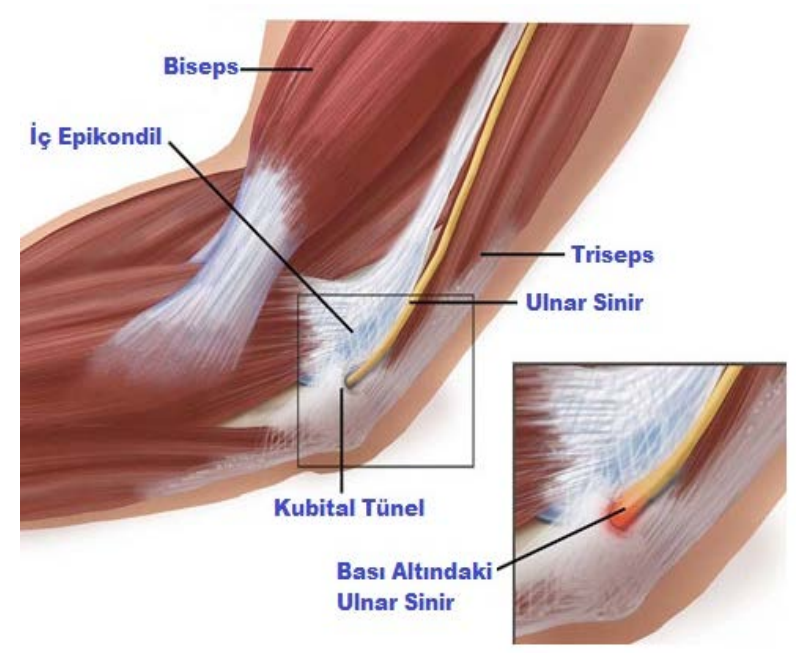

\section{Guyon kanalı sendromu}

El bileğinde ulnar sinirin içte hamatumun çıkıntısı ve psiform'dan kanal çatısının palmar fasya ve palmaris brevis'den oluşan Guyon kanalı içinde sıkışması ile oluşur. Ganglion kisti, inflamatuar hastalıklar sıkışma nedeni olabilir. Tedavi konservatiftir (19).

Radial Sinir Tuzak Nöropatileri

Radial sinir, C5-T1 brachial pleksus posterior kökünden innerve olıur.

\section{Aksiller bölgede sıkışma}

Koltuk değneğinin yanlış kullanılması sonucu radial sinirin aksiller bölgede baskıya uğraması sonucu oluşur. Triceps ve distal kaslarda güçsüzlük oluşur. Tümoral sebepler ve travma da sıkışmada etkilidir (19).

Üst kolda sıkışma 
Radial sinirin humerus başında dönerek seyretmesi sırasında baskıya maruz kalmasıyla oluşur. Alkol veya uyku sırasında kolun kötü pozisyonda kalması sonucu oluşur. Humerustaki kırıklar, tümoral nedenler ve triceps kasının aşırı kullanımı sonucu da gelişebilir. Konservatif tedavi tercih edilir $(19,20)$.

\section{Posterior interosseöz Sinir (Pis) Sendromu:}

Radial sinir, radius başı hizasında, yüzeyel superfisiyel duyu dalı ve posterior interosseöz motor dal olmak üzere ikiye ayrılır. Pis sendromunda sinir, önkol proksimalinde, dirsek kapsülünün önünde veya supinatör kas içerisinde sıkışabilir. Bu noktalarda radial sinirin tuzaklanmasının nedeni, radius baş kırıkları, tümörler, tekrarlı pronasyon-supinasyon hareketi gibi nedenlerdir. Pis sendromunda bilek ekstansörleri intaktır, çünkü bu kasların innervasyonu dirsek eklemi seviyesindedir. Pis sendromunda, parmak ekstansörlerinde, başparmak ekstansör ve abduktorlerinde paralizi gelişir. Duyu defisiti yoktur. Klinik muayenede, lateral epikondilit ile karıştırılabilir. Lateral epikondilit sendromunda, lateral epikondil üzerinde yoğunlaşan ve el bileğinin dirençli ekstansiyonu ile artan bir ağrı vardır. Pis sendromunda ise, ağrı üçüncü parmağın dirençli ekstansiyonu ile şiddetlenir olur ve kolun lateraline doğru yayılır. Ayrıca, dirençli supinasyon hareketi de ağrıya neden olur $(1,3)$. Konservatif tedavide ağrı ve inflamasyonu azaltmak için, dirsek fleksiyonda, önkol supinasyonda, bilek nötral pozisyonda, uzun kol splinti tercih edilebilir. Splint, 46 hafta boyunca, ağrı azalana kadar, gün içerisinde mümkün olduğu kadar çok kullanılmalıdır. Dirsek çevresine uygulanacak klasik masaj, ödemi ve ağrıyı azaltmak için etkili bir yöntemdir. Ayrıca, ağrıyı azaltmak için tens cihazı gibi diğer klasik fizik tedavi ajanlarından da yararlanılabilir. Radial sinir kaydırma egzersizlerine, olabilecek en erken dönemde, kontrollü olarak başlanmalıdır. Semptomlar hafifledikçe, programa kuvvetlendirme egzersizleri eklenmelidir $(3,9,12,13)$. Konservatif tedaviden başarı elde edilemezse, dekompresyon cerrahisine gidilir. Cerrahi sonrası da yine splintleme, fizik tedavi modaliteleri ve egzersizlere başlanmalıdır $(3,9,13)$.

\section{Yüzeyel kutanöz radial sinir sıkışması (keraljiya parestetika- Wartenberg sendromu}

Radial sinirin yüzeyel ve duyu dalının baskı altında kalması ile oluşur. Sinirin ön koldaki seyri sırasında herhangi bir bölgede baskıya maruz kalabilir. Dirsekte efüzyon, tümoral nedenlerle, ön kolda brakiyoradiyal kasın tendonu tarafından daha distalde sıkı bilek bandajları, saat kayışı, bilezik ve radius kırıkları sonucu kallus oluşumu radiyal sinirin tuzaklanmasına neden olur. El sırtında ve radial kesimde ağrı ve parestezi oluşur. Tedavi konservatiftir, nadiren cerrahi gerekir (19).

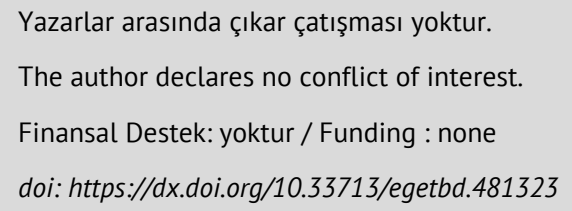

\section{KAYNAKLAR}

1. Allieu $\mathrm{Y}$, Mackinnon $\mathrm{SE}$, editors. Nerve compression syndromes of the upper limb. London: Martin Dunitz; 2002.

2. Lundborg G,Dahlin LB. The pathophysiology of nerve compression. Hand Clin 1992;8(2):215-27.

3. Cooper C. Fundamentals of Hand Therapy: Clinical Reasoning and Treatment Guidelines for Common Diagnoses of the Upper Extremity, 2nd ed. Elsevier Health Sciences; 2013. 5.

4. Hammert WC, Calfee RP, Bozentka DJ and Boyer Ml, editors. ASSH Manual of Hand Surgery. Philadelphia: Lippincott, Williams \& Wilkins; 2010.

5. Alba C. Therapist's management of radial tunnel syndrome. In: Mackin EJ, Callahan AD, Skirven TM, Schneider LH, Osterman $\mathrm{AL}$, Hunter JM, editors. Rehabilitation of the hand and upper extremity, 5th ed. St. Louis: Mosby; 2002 p.696-700.

6. Nai. Wen Tsai, Lian. Hui Lee, Chi. Ren Huang et al. The diagnostic value of ultrasonography in carpal tunnel syndrome: a comparison between diabetic and non. diabetic patient. BMC neurology. 2013; 13:65

7. Tunç A, Güngen B. Karpal Tünel Sendromu Hastalarında Elektrodiagnostik Evreleme ile Klinik Evre, Semptom Süresi ve Vücut Kitle İndeksi Arasındaki Iliş̧kinin Değerlendirilmesi. Dicle Tıp Dergisi 2017;44: 159. 166.

8. Kane PM, Daniels AH, Akelman E. Double Crush Syndrome. J Am Acad Orthop Surg 2015;23(9):558-62.

9. Pecina MM, Krmpotic. Nemanic J, Markiewitz $A D$, editors. Tunnel syndromes. New York: CRC Press; 1991.

10. Bardak AN, Alp M, Erhan B, Paker N, Kaya B, Onal AE. Evaluation of the clinical efficacy of conservative treatment in the management of carpal tunnel syndrome. Adv Ther 2009;26(1):107-16.

11. Yıldırım $P$, Yildirim A, Misirlioglu TO, Evcili G, Karahan AY, OH Gunduz. Recovery features in ulnar neuropathy at the elbow. J Phys Ther Sci. 2015;27(5):1387. 1389. 
12. Evans RB. Therapists management of carpal tunnel syndrome. In: Mackin EJ, Callahan AD, Skirven TM, Schneider $\mathrm{LH}$, Osterman AL, Hunter JM, editors. Rehabilitation of the hand and upper extremity. St Louis: Mosby; 2002.

13. Gerritsen $A A$, de Krom MC, Struijs MA, Scholten RJ, de Vet HC, Bouter LM. Conservative treatment options for carpal tunnel syndrome: a systematic review of randomised controlled trials. J Neurol 2002;249(3):272-80.

14. Peters S, Page MJ, Coppieters MW, Ross M, Johnston V. Rehabilitation following carpal tunnel release. Cochrane Database Syst Rev 2013;6:CD004158

15. Eversmann WW. Proximal median nerve compression. Hand Clin 1992;8(2):307-15.

16. Colditz JC. Splinting the hand with a peripheral nerve injury. In: Mackin EJ, Callahan AD, Skirven TM, Schneider LH, Osterman $A L$, Hunter JM, editors. Rehabilitation of the hand and upper extremity, 5th ed. St. Louis: Mosby; 2002. p.622-34.

17. Karahan AY, Arslan $S$, Özen KE, Öncü F, Bakdık S, Çiçekcibaşı A. Türk toplumunda median ve ulnar sinirlerin ultrasonografik değerlendirilmesi ve antropometrik ölçümlerle ilişkisi. Aegean J Med Sci 2018;1: 13. 18.

18. Shi Q, MacDermid JC. Is surgical intervention more effective than non. surgical treatment for carpal tunnel syndrome? A systematic review. J Orthop Surg Res 2011;6:17

19. Ay S, Evcik D. Tuzak nöropatiler Romatoloji e. kitap 2018.

20. Karahan AY, Arslan S, Ordahan B, Bakdik S, Ekiz T. Superb Microvascular Imaging of the Median Nerve in Carpal Tunnel Syndrome: An Electrodiagnostic and Ultrasonographic Study. J Ultrasound Med 2018;37(12):2855. 2861.. 